\title{
Why do chemistry students need to take mathematics courses?
}

\author{
Andualem Tamiru Gebremichael \\ Universitetet i Agder, Department of mathematical sciences, Kristiansand, Norway \\ For correspondence: andualemtam@yahoo.com
}

\begin{abstract}
Students tend to ask why they should learn mathematics lessons or courses. This study investigates the perceptions of chemistry students and their instructors about the relevance of mathematics courses to their field of study. These students take two mathematics courses during their first year in the university. The major applications of these courses come during the second semester of their first year, their second and third years of study. Cultural historical activity theory, particularly, Engeström model is used as a lens. I undertook individual and group interviews with first, second and third year chemistry students. I also interviewed the mathematics instructors and a chemistry instructor. I examined the curriculum of the program as well as the course outline of the mathematics courses. The students were selected based on their level of achievements: high, medium and low achievers. Four themes emerged from the analytic process. I found out that the students perceive that most of the topics in the mathematics courses were irrelevant to chemistry when they are learning them. Their perceptions seem to change as they progress in their years of study. The curriculum materials lack detail information about the rationale of the course in terms of its relevance to chemistry. The results have implications to the curriculum of the chemistry degree program. In addition to the rationales for the courses, the issues that need to be addressed in connection with the curriculum of the program are set out.
\end{abstract}

Keywords: mathematics, motivation, other school subjects, perception, relevance.

\section{Introduction}

Students tend to ask why they should learn mathematics lessons or courses. While teaching applied mathematics for first year applied chemistry students, one student asked me "the course says applied mathematics, but I didn't see any application in chemistry till now". The problem of gap between the service mathematics course and the application in chemistry is not special to the Ethiopian context. It seems to be a problem in the other counties too (e.g. Witten, 2005). Attempts are made to resolve this problem through designing an additional interdisciplinary course (ibid). Witten (2005) reports on the significance of an interdisciplinary course in bridging the gap between the mathematics knowledge and the utilization of their knowledge in chemistry. Witten's study is not about students' perceptions of relevance. It is not about students' motivation.

The students' perception about the relevance of mathematics is important in their learning. The students' perceptions about the relevance of tasks to their goals are motivational factor to their engaging in it (Eccles \& Wigfield, 2002). Students' motivation to engage in mathematical tasks affects their performance (Hannula, 2006).

Studies on university students' perceptions about the relevance of mathematics to science fields of study are rare. Particularly it is very rare in the context of developing nations where resources are scarce. My study was undertaken in Ethiopia. Particularly at Ambo College (which has now become a university). It is located at Ambo town, $120 \mathrm{kms}$ west of the capital, Addis Ababa. It was established in 1939. In 2003 it was affiliated to Jimma University. It attained a university status in 2008. During the data collection in early 2008, the college was offering Bachelor of Education in chemistry. This program was launched in 2003. It was also offering a Bachelor of Science in chemistry, which was launched in 2006. The curricula of the programs for Bachelor of Education in chemistry and Bachelor of Science in chemistry are adopted from the Addis Ababa University. In both programs there were two compulsory mathematics courses, each has 4 credit hours. The mathematics courses are offered during the students first year of study. 
The department of mathematics was newly established. Resources were scarce. Mathematics reference books were rarely available for the students in the library. In general, the students did not afford buying mathematics books that were required for the courses. There was internet service at the department but it was often unstable and very slow. The internet service was not available for the students.

The research question I attempt to answer in this study is: how do chemistry students perceive the relevance of the mathematics courses to chemistry? This paper is structured as follows: the theoretical framework, methodology and results are presented in this sequence. The results section has four subsections. Finally, the conclusion is provided.

\section{Theoretical framework}

In this study I employ cultural historical activity (CHAT). Particularly, I adopt Engeström's triangle which models activity as an object-oriented and mediated by tools and artifacts (Cole \& Engeström, 1993). In Engeström's mediational triangle, the student interacts with the object. This can be mediated by the books, computers, etc. According to Engeström the mediational process also involves community, division of labor and rules (Cole \& Engeström, 1993). Participants involve in an activity and have a motive for involving in the activity (Leont'ev, 1979). In order to realize the activity participants undertake actions, which are directed towards goals (ibid). Their actions are realized through undertaking operations which are conditioned by the situation around (ibid). In activity theory the main focus is on the activity. The goals and operations are meant to realize the activity (ibid).

The students in this study participate in the activity of university study with the motive of attaining an academic degree. In the university or college setting, the possible motive is an academic degree. The object of the activity consists of their motive, their goal of learning chemistry, their goal of learning mathematics and other courses. The students undertake various actions such as attending classes, studying particular topics, engaging in group work, etc. (cf. Leont'ev, 1979). These actions are directed towards the goal of learning mathematics, chemistry and other courses. In doing so, the students realize their activity of university study.

This process is mediated by tools and signs. It is also mediated by the university's or colleges' rules. Their mathematical knowledge is measured by the examinations, in accordance with the rule in the activity of university study. The rule enforces that the students should do the mathematics examinations. According to the division of labor in the university the department of mathematics has to offer courses in applied mathematics for chemistry students. In the process of undertaking the course, the students and the instructor have predefined roles. The limited resource might sometimes violet the division of labor. For example, students tend to be dependent on the teacher because there is scarcity of books in the library and the students do not afford to buy books. In this activity, the community, the division of labor, and the rules mediate their perceptions and also form the structure in which their perceptions are formed (cf. Roth, Tobin, Elmesky, Carambo, McKnight \& Beers, 2004).

The students are participating in the historically situated activity of university study. There has been the activity of university study before these students joined the university. The students exploit the prior experiences of others including their teachers and senior students. Their perceptions form and transform while they participate in the activity of university study. In their participation of this activity, the community, the division of labor and the rules mediate their perceptions about the relevance of mathematics. In my study following Vygotsky (1978) perception is understood as the attaching of meaning and making sense of a mathematical experience.

\section{Method and design of the study}

I chose to use the qualitative research methodology because it suites my purpose. Maxwell (2005) describes qualitative research as suited among others for understanding the particular context within which the participants act and the influence that this context has on their actions. According to Merriam (1998) the concern of qualitative research is to understand the phenomenon of interest from the participants' perspective. In particular, interviews were used to collect data. Interviews give an 
opportunity to understand the interviewee through creating a conducive and flexible situation (Kvale, 1996). The interviews were semi-structured. As an interviewer my role was to provide the participants discussion points that guide them to focus on the issue. Based on my understanding of their comments I raise further questions that enrich my data. The students form and transform their perceptions based on new experiences. The process of formation of their perception is not investigated in this study. The report in this study is the investigation of their perception which resulted from their history of learning. Their perception is captured from the interview data

Ambo College was selected because as a member of the College, I had easy access to the required information. The data sources are chemistry students in the college. I employed purposive sampling. I selected students who have various levels of achievements (high, medium, low) in mathematics and in their total score. The first year students did not have grades during the data collection. 16 students were interviewed ( 5 third year, 10 from $2^{\text {nd }}$ year, 1 from first year). The number of female chemistry students was small; 4 participated in the interview. 3 female students from third year were interviewed in group. The rest of the interviews were individual interviews. Since the college runs both applied chemistry and chemistry education degree programs, I interviewed students from both streams. The second year students are from both streams whereas the third year students are from applied stream only. This is because there were no third year students in education program during the data collection. The interview involved semi-structured open-ended questions pertinent to the research problem. The themes emerged through the analytic process were further analyzed using Engeström model. Other supporting data sources are classrooms observation, curriculum of the program, and course outlines. 1 chemistry and 3 mathematics instructors were also interviewed in order to get their views about pertinent issues that are raised by students. Participants were given pseudonyms. The following table presents the participants grade point average and their grades in mathematics.

Table 1. The pseudonyms of participant students, their years of study, their grades in mathematics and their grade point average (GPA) during the first and the second semesters

\begin{tabular}{|c|c|c|c|c|c|}
\hline \multirow[t]{2}{*}{ Name } & \multirow{2}{*}{$\begin{array}{l}\text { Year } \\
\text { of } \\
\text { Study }\end{array}$} & \multicolumn{2}{|l|}{ Semester I } & \multicolumn{2}{|l|}{ Semester II } \\
\hline & & Math Grade & GPA & Math Grade & GPA \\
\hline Bayeh & 2 & C & 2.95 & A & 3.14 \\
\hline Dendir & 2 & A & 3.56 & A & 3.76 \\
\hline Fetene & 2 & C & 2.79 & A & 3.28 \\
\hline Kesete & 2 & A & 3.89 & A & 3.83 \\
\hline Ligaba & 2 & C & 2.00 & C & 2.00 \\
\hline Mume & 2 & C & 3.37 & A & 3.39 \\
\hline Tegbaru & 1 & - & - & - & - \\
\hline Yigrem & 2 & C & 2.38 & C & 2.20 \\
\hline Regassa & 2 & C & 2.00 & C & 1.50 \\
\hline Biniam & 2 & D & 2.05 & B & 2.56 \\
\hline Zegeye & 2 & C & 2.16 & B & 2.06 \\
\hline Frew & 3 & B & 3.22 & B & 3.40 \\
\hline Fisiha & 3 & A & 3.78 & A & 3.80 \\
\hline
\end{tabular}

This table does not contain participants of the focus group interview. All the students listed in the table except Yigrem are male students. This is because the female students who were invited for the interview could not show up. The number of female students in the chemistry programs is small. Yegrem helped in finding 3 other female students (from third year) for the interview. These three students were interviewed in group. Most of the participants of this study are second year students. This is because of their population in the two programs. This is also in accordance with the interest of the study. The second year students have taken both the mathematics courses and have experienced at least one of the physical chemistry courses which significantly apply the concepts they have learnt in mathematics. Moreover, they have fresh memory of their experiences in mathematics and to reflect on their experiences in chemistry. The first year students started the academic year late and they did not have grades during the data collection. The results are presented next. 


\section{Results}

The qualitative data and the data analysis are set out in this section. That is, the results that emerged in the analytic process are presented under four themes. These four themes are: I don't know why I am learning except for its exchange value; Who teaches matters in attaching relevance; Some important topics are not covered, and Why dig deep into the core while the gold is on the surface. The results are presented in these sequence as follows.

\section{I don't know why I am learning except for its exchange value}

Students appear to have little information about why they learn mathematics, till they see its application in chemistry courses. This is revealed in their stories during the discussion about the purpose of the mathematics courses. The first year student, Tigabu says, "... Till now we are learning topics which are not relevant to chemistry. We learnt matrix, determinant and vector." The mathematics lessons mediate his perception of relevance. The students have been learning chemistry for many years. The chemistry programs have been running for many years in this college and in other colleges. Though Tigabu, who belongs to the community of chemistry students, is new to the program he has the exposure about ideas that could relate with chemistry. The rules which enforce that the students should attend to the courses also mediate their perception.

The experience seems to be the same when students are in their first year of the program. The third year applied chemistry student Lakew explains his perception when he was a first year student two years ago. He says, "We were learning mathematics just for the sake of completeness. We were not paying attention other than studying it to score grade." The rules enforce that they should score grades in order to survive in the program. According to the college's rule the courses that the students attend to are weighed by their credit hour, which ranges from 1 to 4 . Each of the mathematics courses has 4 credit hours. Fetene, a second year student, tells his story. He says, "... The mathematics courses [had] bigger credit hours; therefore I gave them more time." The rules do not favor mathematics in terms of attaining relevance to mathematics, but in terms of acquiring students' attention. The rules direct the students' attention. Fetene adds, "I don't pay attention to the knowledge I gain. ...actually, I may gain knowledge when I study.... [in] the course outline, I just look at the credit hour than the other facts on it." The relevance of mathematics appears to shift from having application to chemistry to having an exchange value in attaining good grades, which leads to securing the academic degree in chemistry.

The students explain that knowing that mathematics has an application in their field would be a motivational factor. For example, Tigabu says, I could have studied it with zeal had there been application in chemistry." Neither the curriculum of the program nor the course outline mention why the concepts are important for the students. The curriculum materials (the course outline and the curriculum of program) also mediate their perceptions by limiting the information that they need about the relationship of mathematics and chemistry course. Their perceptions are motivational factor in their engaging. An excerpt from Mume's story also indicates this effect. He says: "If the course outline contains something which derives my interest I will be motivated to study hard in that course. ... ." In the absence of documents that give the details of how and where the chemistry student applies the mathematical concepts the student may not be motivated to learn mathematics. They appear to know that mathematics has use in chemistry after mathematics courses are completed. The students appear to be deprived of the opportunity to be motivated (by its use value) to engage in mathematics. they appear to be motivated by its exchange value only.

Who teaches matters in attaching relevance?

Some students perceive that the teacher matters in attaching of relevance. The second year student, Bayeh shares his experience as first year student. He says, "The mathematics instructor in the second semester ... used to give us examples which are related to chemistry. That motivated me to work more and be successful in the course." The mathematics instructor mediates students' perceptions by directing their attention to what relevance the mathematics has to chemistry. This appears to have a motivational effect. This student scored a ' $\mathrm{C}$ ' grade in the first semester and an ' $\mathrm{A}$ ' grade in the second semester. He gives the credit to the instructor who motivated him by giving examples 
pertinent to his field of study (see also Bayeh's story next section). The mathematics instructor that Bayeh is referring to was no longer a member of the college during the data collection.

Some mathematics instructors suggest that the application of mathematics in chemistry should not be the responsibility of the mathematics instructor. A mathematics instructor, Birhane, says, "it is the chemistry instructor who should know where and how they apply mathematics in chemistry. We know the mathematics and we just teach the mathematics." According to the division of labor in the college the mathematics instructor needs to equip the students with the mathematics knowledge that they need for chemistry. But, it is not clear how much is expected from the mathematics instructor. Some instructors attempt to provide examples of application in chemistry; others commit themselves to the mathematics only. But, should this be left to the individuals' discretion?

\section{Some important topics are not covered}

The students experience the application of mathematics in the chemistry courses and appear to change their perceptions. They perceive that some important topics in mathematics which have application in chemistry are not covered as required. Sometimes, because of time constraint some topics of the first course are transferred to the second course. The second year applied chemistry student, Yigrem, says, "We were applying integral in physical chemistry in the second semester. ... Integral was included in the course outline ... in the first semester. But, due to time constraint we only dealt it in the second semester". The chemistry lessons mediate students' perceptions. According to Yigrem, the students learn about integral in mathematics while the chemistry course that involves the application of integral is being offered. This is as a result of the bulk of the mathematics course which couldn't be completed in the given four credit hours. It is a usual trend in the applied mathematics courses that last chapter of the first course is left to the second course (i.e., to the next semester). Consequently, the last topics in the second course are not covered. Frew, a 3rd year students tells an example. He says, "The portions which are important for physical chemistry are not covered because of time constraint. For example, we didn't learn triple integral and differential equations." The students didn't learn some of the topics which are important to their field of study because of the bulk of contents they should cover. In such cases some instructors tell students the importance of the topics for chemistry. Bayeh, a second year student, tells his experience in the second course. He says, "... [the instructor] was under time constraint to complete the lesson. We did not learn about double integral and he told us that it is important in physical chemistry." Some other teachers try to complete the topic by omitting proofs of a given theorem or by omitting some of the theorem that the instructor feels is less important. For example, Ketema, a mathematics instructor says: ... students should know basic concepts in each topic. ...., to manage completing the course, I state theorems without proving. Sometimes, I omit [less important] theorems." The mathematics instructors as members of the community mediate the students' perceptions.

\section{Why Dig Deep into the Core While the Gold Is on the Surface?}

The senior students perceive that mathematics is relevant. They perceive that the topics are dealt unnecessarily in-depth. The following story from a focus group discussion with third year female students is exemplar, "... the extent to which we learned in mathematics is very deep and complex ...we learnt it like mathematics students." These students are in final year of their study and have been exposed to most of the applications of mathematics in chemistry courses. Their perceptions are mediated by the mathematics and chemistry lessons. The rule also mediates their perception. The rule enforces a wide content coverage and provides limited information about the depth. These students also added, "Our instructor used to say 'this is simple; ... But, we need to understand the simpler ones. ... [they] remained to be areas of problem in the physical chemistry courses." The teacher also mediates their perceptions.

The depth of topics with respect to the needs in chemistry seems important. In one of my classroom observations, the instructor was giving a detailed explanation of vectors for applied chemistry students. I had a brief discussion with him about what guides the depth to which the mathematics topics are dealt. He said, "It is the course outline that guides me what to include .... In addition, the allotted time limits me to what extent I should go. ...". Another mathematics instructor, Ketema, suggest that a standard text book as a guide. He said, "We have the course description .... also the 
course outline .... We have the time limit for each topic. Based on these we limit the depth .... Otherwise there are no text books which could have limited the scope of a given course." A textbook, which Ketema is referring to is not available in the system. It appears that to decide about the depth of a topic is left to the discretion of the teacher.

Gudissa is a chemistry instructor. I had an interview with him about the importance of mathematics courses to the chemistry courses. He says, "Physical chemistry makes use of many mathematics concepts. We use integral, double integral, triple integral, as well as determinant." It appears that the mathematics concepts are significant for the chemistry courses. But students do not seem to be aware while they were taking the courses. This is particularly true during the first course.

Though some concepts seem irrelevant to chemistry, the mathematical relationships necessitate their inclusion. For example the concepts of limit are important in order to learn derivatives. The concepts of derivatives are important in order to learn integrals. Students need to have some knowledge of algebra in order to learn determinants. These relationships of the topics seem to be unavailable for the student beforehand. Though it seems that the mathematics concepts that the students are learning are relevant to the chemistry courses, the depth to which it needs to be dealt is largely determined by the individual teacher. On the other hand, some topics will be left uncovered at the end of the semester and at the end of the academic year. The topics which are left uncovered are useful for the physical chemistry course.

\section{Conclusion}

During the first year students tend to perceive that the mathematics course that they are taking is not relevant to their field of study (i.e., chemistry). This is the case particularly when the first course was running. Their perceptions appeared to change when they began to experience some calculus in the chemistry course during the second semester. The students were not aware beforehand. They are not informed from the beginning about the use of mathematics in their field of study. They seem to miss the opportunity of being motivated to engage in mathematics by its application. The students tend to learn mathematics only for its exchange value. When there are exceptions to this, it is because of the individual mathematics instructor. The students' perceptions of relevance were mediated by the mathematics instructor, the rules, the curricular materials and the division of labor.

This study has implication for the curriculum of the chemistry degree program. The curriculum of the program should have a clear guideline about the contents and the depth to which contents (the mathematical concepts) are dealt. A detailed account of why the student is learning each topic/lesson should be stated in the curriculum or other related material. The chemistry program needs to explicitly address the usefulness of its service courses. The students and mathematics instructor needs to know the significance of the topics and the level of significance to the students' future use in the chemistry courses. This also suggests that there is a need for a close collaboration and dialogue across the departments/disciplines. The vast content, about which both instructors and students are complaining, need some intervention action. The instructors suggested an additional (a third) course for completion of the content. On the other hand, making a link between the mathematical concepts and their application in chemistry is a challenge for the students (cf. Witten, 2005). Designing an additional course that can address both problems seems important alternative to consider.

In this research report I have attempted to explore and expose the chemistry students' perceptions about the relevance of mathematics to their field. This study also exposes that the students' awareness about application of mathematics to their field of study is motivational factor. Further data analysis, in terms of the tensions that the students experience, is underway. It also remains to examine how widely the students' perceptions are held. Based on the results of this study questionnaires will be developed to respond to this question. In this study the report is mainly about chemistry students. The chemistry instructor and the mathematics instructors were interviewed for the sake of getting their views with respect to issues raised by students. Future studies need to consider a detail account of the instructors. 


\section{References}

Cole, M., \& Engström, Y. (1993). Cultural-historical approach to distributed cognition. In G. Salomon (Ed.), Distributed cognitions: Psychological and educational considerations (pp. 1-43). Cambridge, UK: Cambridge University Press.

Eccles, J. S., \& Wigfield, A. (2002). Motivational beliefs, values, and goals. Annual Review of Psychology, 53, 109-132.

Hannula, M. S. (2006). Motivation in mathematics: Goals reflected in emotions. Educational studies in mathematics, 63, 165-178.

Kvale, S. (1996). InterViews: An introduction to qualitative research interviewing. Thousand Oaks, CA: Sage Publishing.

Leont'ev, A. N. (1979). The problem of activity in psychology. In J. V. Wertsch, (Ed.), The concept of activity in soviet psychology (pp. 37-71). New York: M. E. Sharpe.

Maxwell, J. A. (2005). Qualitative Research Design: an Interactive Approach (2nd Ed). USA: SAGE Publications.

Merriam S. B. (1998). Qualitative Research and Case Study Applications in Education: Revised and Expanded from Case Study Research in Education. San Francisco: Jossey-Bass.

Price, S. and Hill, O. (2004) Raising the status of chemistry education. http://www.rsc.org/Education/CERP/issues/20041/raising.asp Accessed January 9, 2007.

Roth, W-M., Tobin, K., Elmesky, R., Carambo, C., McKnight, Y-M., \& Beers, J. (2004). Re/Making Identities in the Praxis of Urban Schooling: A Cultural Historical Perspective. Mind, Culture, and Activity, 11, 48-69.

Vygotsky, L. (1978). Mind in society: The development of higher psychological processes. Cambridge, MA: Harvard University Press.

Witten, G. Q. (2005). Designing mathematics course for chemistry and geology students. Educational Studies in Mathematics, 58 (1), pp. 1-19 